\title{
A abordagem microgenética na matriz histórico-cultural: Uma perspectiva para 0 estudo da constituição da subjetividade
}

\author{
Maria Cecília Rafael de Góes *
}

\begin{abstract}
RESUMO: Este trabalho focaliza a análise microgenética enquanto abordagem metodológica que está inscrita numa interpretação histórico-cultural e semiótica dos processos humanos e que é distinta de formas de análise de microeventos ligadas a outros aportes teóricos. O propósito é caracterizar, dentro da matriz histórico-cultural, a vertente dessa abordagem que articula o nível microgenético das interações sociais com o exame do funcionamento dialógico-discursivo, salientando, ainda, as propostas de vinculação com as proposições do paradigma semióticoindiciário. É salientado o caráter promissor de tais tendências para a investigação da constituição do sujeito, pois elas permitem adensar o estudo dos processos intersubjetivos e expandem as possibilidades de vincular minúcias e indícios de episódios específicos a condições macrossociais, relativas às práticas sociais.
\end{abstract}

Palavras-chave: Análise microgenética, matriz histórico-cultural, paradigma indiciário, intersubjetividade, processos dialógicos

$\mathrm{Na}$ investigação sobre a constituição de sujeitos, em especial no que concerne a processos que se instanciam nos contextos educativos, os campos da educação e da psicologia vêm recorrendo a uma abordagem metodológica referida como "análise microgenética". De um modo geral, trata-se de uma forma de construção de dados que requer a atenção a detalhes e o recorte de episódios interativos, sendo o exame orientado para o funcionamento dos sujeitos focais, as relações intersubjetivas e as condições sociais da situação, resultando num relato minucioso dos acontecimentos. Freqüentemente, dadas as demandas de registro implicadas,

\footnotetext{
* Docente da Faculdade de Educação da Universidade Metodista de Piracicaba. E-mail: mcgoes@iepmail.unimep.br
} 
essa análise é associada ao uso de videogravação, envolvendo o domínio de estratégias para a filmagem e a trabalhosa atividade de transcrição. A análise microgenética pode ser o caminho exclusivo de uma investigação ou articular-se a outros procedimentos, para compor, por exemplo, um estudo de caso ou uma pesquisa participante.

O propósito deste trabalho é delinear as características peculiares à análise microgenética, em sua vinculação com a matriz histórico-cultural, para, de um lado, distingui-la de outras análises de microeventos referenciadas em correntes teóricas diferentes e, de outro lado, ressaltar o caráter profícuo desse caminho metodológico no estudo de questões referentes à subjetivação em sua necessária relação com o funcionamento intersubjetivo.

Existem abordagens analíticas que enfatizam a necessidade de registros detalhados, mas distanciam-se da metodologia ora considerada por estarem inscritas em referenciais teóricos que não assumem a centralidade do entrelaçamento das dimensões cultural, histórica e semiótica no estudo do funcionamento humano. Nesse sentido, vale mencionar, a título de ilustração, as descrições minuciosas de comportamentos, arranjos do ambiente e formas de relação entre comportamento e condições ambientais, nos estudos etológicos; noutra corrente teórica, tem-se as pesquisas comportamentalistas, que efetuam um detalhamento de estímulos, respostas, eventos conseqüentes, seqüências comportamentais etc.

Um caminho teórico-metodológico diverso destes, mas também voltado para as minúcias, e cada vez mais empregado na investigação de processos intersubjetivos, com presença significativa no estudo do cotidiano escolar, é a abordagem microetnográfica. Ela insere-se na proposta da etnografia, que deriva da matriz antropológica cultural e implica a descrição ou reconstrução analítica do cenário e das regras de funcionamento de um grupo cultural. Trata-se também de uma reconstrução que se guia pela concepção de mundo ou quadro conceitual dos investigados. Fazendo parte dessa perspectiva, a microetnografia é definida por Streeck (1983) como a análise de microcomportamentos que compõem processos organizacionais da interação social. André (1997), ao comentar as tendências da etnografia nos estudos da escola, reporta-se ao crescente interesse pela microetnografia, a qual privilegia "o como acontece", diferentemente da etnografia em geral, que estuda "o que acontece". A autora também aponta o fato de que, nesse caso, o apoio usual na documentação em vídeo faz com que os procedimentos em questão requeiram determinados conhecimentos técnicos, além do suporte teórico. 
À primeira vista, nota-se uma proximidade da análise microetnográfica com a microgenética, pois esta última está igualmente orientada para os detalhes das ações; para as interações e cenários socioculturais; para o estabelecimento de relações entre microeventos e condições macrossociais. Por outro lado, uma primeira característica distintiva pode ser identificada, não no termo micro em si, mas na sua qualificação como genética, o que parece estabelecer um contraste com o aporte etnográfico ${ }^{1}$. A visão genética aí implicada vem das proposições de Vygotsky $(1981,1987 a)^{2}$ sobre o funcionamento humano, e, dentre as diretrizes metodológicas que ele explorou, estava incluída a análise minuciosa de um processo, de modo a configurar sua gênese social e as transformações do curso de eventos. Essa forma de pensar a investigação foi denominada por seus seguidores como "análise microgenética".

Entretanto, se esse critério genético diferencia a categoria metodológica de outras análises de microeventos, é importante lembrar que a forma como vem sendo empregado o qualificativo "microgenético" mostra que ele não tem filiação teórica única. O próprio Piaget, em seu modelo de método clínico, usou estratégias que poderiam ser consideradas microgenéticas, e seus seguidores referem-se à necessidade de que os estudos, nesse método, envolvam o exame crítico e minucioso das ocorrências nas sessões de provas ou entrevistas (por exemplo, Castorina, Lenzi e Fernández, 1988). Isso porque se busca compreender os passos do desenrolar das ações dos sujeitos e explicar suas construções e transformações cognitivas. É preciso acrescentar, ainda, que a proposta de entrevista clínica de Piaget (pelo menos na versão da década de 20 - Piaget 1978, original de 1926) teve repercussão sobre o próprio trabaIho ontogenético de Vygotsky, como relata Luria (1988a), e, presumivelmente, afetou as formas pelas quais ele realizava análises detidas de seqüências de acontecimentos em sessões de pesquisa. Naturalmente, Vygotsky transformou muito a idéia original - que era de uma busca cuidadosa das respostas "espontâneas" da criança, não influenciadas pelo adulto - e introduziu deliberadamente pistas, auxílios ou obstáculos, para estudar os processos de interesse. A mudança no formato da entrevista não é mero detalhe, mas decorre da tese fundamental de Vygotsky, segundo a qual os processos humanos têm gênese nas relações com o outro e com a cultura, e são essas relações que devem ser investigadas ao se examinar o curso de ação do sujeito.

Constata-se, então, que também entre as visões genéticas é possível identificar uma diferença de fundamental importância - entre um 
enfoque psicogenético e outro sociogenético. Mas essa identificação constitui, ainda, uma marca parcial de diferenciação da análise de microeventos na visão vygotskyana.

Para acrescentar aspectos distintivos dessa abordagem, passo a apresentar algumas proposições de ordem epistemológica e metodológica defendidas por Vygotsky, para, posteriormente, comentar o trabalho atual de autores da matriz histórico-cultural. Esclareço que se trata de uma retomada seletiva das idéias daquele teórico, de maneira que não serão exploradas todas as questões importantes por ele discutidas nesse âmbito.

As contribuições metodológicas

de Vygotsky e a análise microgenética

Para Vygotsky (1984), "o método é, ao mesmo tempo, pré-requisito e produto, o instrumento e o resultado do estudo", (p. 74). Trata-se de uma visão abrangente, à qual ele vincula a possibilidade de vários tipos de investigação e diretrizes metodológicas amplas que buscam atender a duas teses fundamentais: de que a gênese das funções psicológicas está nas relações sociais e de que a constituição do funcionamento humano é socialmente mediada, num curso de desenvolvimento que abrange evoluções e, sobretudo, revoluções. Essas teses distinguem suas proposições de outras teorias em que, de um lado, o "genético" é fragilmente relacionado ao meio social e, de outro, o desenvolvimento é concebido como um curso de etapas progressivas. Tendo em vista a crença no papel fundante das relações sociais, $o$ autor concebe o estudo do homem enquanto ser que se constitui imerso na cultura - nas experiências coletivas e práticas sociais - e como produtor-intérprete de sistemas semióticos. Em sua obra, são recorrentes, e por vezes densas, as discussões sobre o signo, a palavra e a linguagem, temas esses que o ajudam a configurar a especificidade do humano e que, como ele ressalta, demandam caminhos metodológicos diferentes daqueles utilizados nas ciências naturais. Portanto, no que concerne ao método, a investigação não pode descolar-se de uma visão sociogenética, histórico-cultural e semiótica do ser humano, sendo que as proposições conceituais e metodológicas devem ser interdependentes e congruentes teoricamente.

Alguns princípios metodológicos são apresentados sucintamente em seu texto "Problemas de Método" (Vygotsky 1984), em que ele propõe o estudo de processos e não de produtos ou objetos, pois "é somente em movimento que um corpo mostra o que é" ( $p$. 74). Argumenta pela 
necessidade de examinar a dimensão histórica e alerta para o fato de que privilegiar a história não é estudar eventos passados, mas sim o curso de transformação que engloba o presente, as condições passadas e aquilo que o presente tem de projeção do futuro. Inclui nessas diretrizes a importância de se identificar relações dinâmico-causais, devendo o investigador buscar distinguir a aparência e os processos da dinâmica subjacente. A expressão dinâmico-causal corresponde também à idéia de que causa e efeito não são entidades de posição imutável. A causa pode transformar-se em efeito e este em causa, dinamicamente.

Segundo Wertsch (1985), a tese da constituição cultural dos processos humanos, a visão de desenvolvimento humano e a preocupação com a dimensão histórica levaram Vygotsky a abordar vários domínios genéticos: a filogênese, a história sociocultural, a ontogênese e a microgênese. Assim, realizou discussões sobre a evolução da espécie, a emergência do especificamente humano e as características das sociedades "primitivas" (Vygotsky e Luria 1996), tendo colaborado em estudos sobre comunidades em transformação (ver Luria 1988b). Focalizou especialmente o domínio ontogenético, mas efetuava um entrecruzamento dos estudos da ontogênese e da microgênese, sempre relacionando os dois níveis de análise, isto é, investigava questões ontogenéticas (abrangendo diferentes faixas etárias) e se deslocava para outro nível de estudo que envolvia sessões examinadas nas minúcias de transformação das respostas dos sujeitos. Essa perspectiva pode ser notada nos trabalhos sobre relações entre pensamento - linguagem, atenção, memória, formação de conceitos, fala egocêntrica, desenvolvimento da imaginação etc. (Vygotsky 1984, 1987a, 1987b).

Ainda que em alguns desses domínios (por exemplo, da história sociocultural) não tenha havido um investimento mais denso, o mérito de Vygotsky está na proposição de uma visão ampla da investigação histórico-cultural. Quanto ao tema específico que interessa aqui, sua contribuição se estende à forma promissora de considerar o nível dos detalhes dos processos.

É importante esclarecer que essa atenção às minúcias de um curso de transformação das ações do sujeito nada tinha a ver com o privilegiamento de elementos isolados, com base nos quais seriam estabelecidas leis associativas para explicar o comportamento complexo. A esse respeito, Vygotsky (1985) foi contundente em sua oposição ao elementarismo:

Decompostos em seus elementos, os processos superiores e mais complexos foram inteiramente reduzidos a processos mui- 
to diferentes do ponto de vista de sua complexidade e sua forma; obtinha-se, assim, um gigantesco mosaico da vida psíquica feito de pedaços isolados da experiência: um panorama atomista grandioso do espírito humano desarticulado. (p. 28)

Como o elementarismo vinculava-se, necessariamente, aos modelos que focalizavam a associacão como princípio básico do estudo do homem, Vygotsky (1985) também teceu críticas ao associacionismo, tanto o de caráter naturalista-biologizante quanto aquele de inspiração subjetivista. Afirmava que, nessas matrizes, as formas superiores de comportamento

ou são assimiladas ao processo fisiológico do organismo e seu desenvolvimento se reduz, então, ao período dos primeiros anos da vida (...), ou são separadas de todo elemento material e consideradas como a manifestação de uma nova vida, eterna, livre e extratemporal, ideal e acessível unicamente por uma pesquisa intuitiva que toma a forma de uma "matemática atemporal do espírito". Ou uma ou outra. Fisiologia ou matemática do espírito, e não a história do comportamento humano compreendido como um aspecto da história geral da humanidade. (p. 34)

Assim, o nível microanalítico, de base histórico-cultural, afasta-se totalmente do estudo de elementos e leis de associação. Aliás, Vygotsky (1987a) contrapõe-se à análise por elementos, propondo a busca de uma análise por unidades e definindo a unidade como aquela instância de recorte que conserva as propriedades do todo que se pretende investigar. Alega que essa noção é mais apropriada porque, diferentemente do elemento, a unidade é o componente vivo do todo.

\section{Contribuições atuais para a discussão da análise microgenética}

Wertsch (1985), com base nas proposições e pesquisas de Vygotsky, define a análise microgenética como aquela que envolve o acompanhamento minucioso da formação de um processo, detalhando as ações dos sujeitos e as relações interpessoais, dentro de um curto espaço de tempo. Essa duração corresponde a uma ou poucas sessões, em delineamentos planejados ou a curtos segmentos interativos, em situações naturais. É uma espécie de "estudo longitudinal de curto prazo" e uma forma de identificar 
transições genéticas, ou seja, a transformação nas ações dos sujeitos e a passagem do funcionamento intersubjetivo para o intra-subjetivo. Portanto, desse ponto de vista, é destacado o exame de processos interativos e de pistas de internalização. O estudo de Wertsch e Hickmann (1987), que ilustra essa interpretação, focaliza uma díade mãe - criança, numa atividade com um jogo de quebra-cabeças, estando a análise orientada para os detalhes de movimentos e falas dos dois sujeitos e para os indicadores de internalização de ações pela criança. ${ }^{3}$

Apesar da pertinência das considerações de Wertsch, julgo que elas não chegam a caracterizar plenamente esse tipo de análise. Nota-se que, nessa definição, as indicações criteriais estão postas na transição genética (do intersubjetivo para o intra-subjetivo) e na questão da curta duração dos eventos estudados. Em termos da primeira indicação, é preciso lembrar que as relações entre processos intersubjetivos e intra-subjetivos, por serem fundamentais nessa matriz teórica, marcam os esforços de investigação em geral, principalmente em termos do domínio ontogenético; portanto, trata-se de um apontamento apropriado, mas não como critério diferencial suficiente do plano da microgênese. Quanto à duração, não parece ser um critério, em si e por si. O estabelecimento de um período curto de tempo parece decorrer da necessidade de recortes que permitam examinar as minúcias. Tanto assim, que, nos relatos de pesquisa, não há usualmente mensuração do tempo dos episódios recortados. Às vezes é mencionado o tempo total de um episódio; excepcionalmente, indica-se, se isso for significativo para a análise, a duração de lapsos de tempo entre um acontecimento e outro, dentro de um episódio. Ademais, diferentes trabalhos contêm números e durações diversas de segmentos interativos, e o mesmo trabalho pode apresentar episódios com durações variadas. Em outras palavras, não há critérios postos quanto a recortes temporais para a configuração de uma análise microgenética.

Em resumo, essa análise não é micro porque se refere à curta duração dos eventos, mas sim por ser orientada para minúcias indiciais daí resulta a necessidade de recortes num tempo que tende a ser restrito. É genética no sentido de ser histórica, por focalizar o movimento durante processos e relacionar condições passadas e presentes, tentando explorar aquilo que, no presente, está impregnado de projeção futura. É genética, como sociogenética, por buscar relacionar os eventos singulares com outros planos da cultura, das práticas sociais, dos discursos circulantes, das esferas institucionais.

As ressalvas feitas a Wertsch devem-se, assim, ao fato de que, em sua definição, a duração e a transição genética são salientadas, enquanto 
fica apenas subentendido o vínculo fundamental com o exame das minúcias e das dimensões semiótica, histórica e cultural. Para fazer justiça às produções desse autor, é importante reconhecer que ele não descuida dessas dimensões em sua obra. Ao contrário, é um dos seguidores de Vygotsky que mais enfatiza a questão semiótica, e o faz de maneira muito interessante, ao relacioná-la com os temas da enunciação e da dialogia (o que se encontra evidenciado, dentre outros textos, em Wertsch 1991). É um mérito a ser registrado, porque muito da teorização atual na matriz históricocultural não se ocupa com tal perspectiva. Desse modo, o que está em questão, neste momento, é a definição que ele propõe para a abordagem microgenética e que, em nossa realidade, tem guiado um razoável número de pesquisas sobre processos interativos. Sua formulação é freqüentemente referida nos trabalhos brasileiros, mas, como será esclarecido a seguir, aparecem muitas variações interessantes na implementação dos estudos, de maneira que se poderia dizer que a caracterização proposta por Wertsch tem um papel de "quase" modelo.

Assim, a partir dessa referência, os pesquisadores têm efetuado investigações produtivas na abordagem histórico-cultural, focalizando os aspectos intersubjetivos e dialógicos, recortando o material documentado em poucos ou vários episódios que sejam significativos para o propósito do estudo, buscando traçar o curso de transformações. Meira (1997) aponta contribuições da análise microgenética para a psicologia cognitiva e, recorrendo a Wertsch (1985) e outros pesquisadores, propõe-se a entendê-la como uma microanálise interpretativa para fins de estudos cognitivo-interacionais. Apresentando um relato de pesquisa sobre as formas pelas quais estudantes elaboram representações matemáticas, o autor esclarece que, em pesquisas desse tipo, devem ser valorizados os processos e os conteúdos semânticos, abrangendo a descrição cuidadosa da interação em episódios prototípicos, em termos das ações cognitivas, comunicativas e gestuais. Os dados são interpretados na direção de uma minuciosa apresentação narrativa e explicativa.

A investigação de processos cognitivos construídos nas interações é, contudo, uma das vertentes dessa metodologia. Rojo (1997), ao discutir as formas de estudo minucioso de processos interativos, distingue três orientações: a cognitivista, que focaliza o plano intrapessoal durante os eventos interativos; a interacionista, que examina as relações interpessoais e o jogo conversacional como condição para a formação do funcionamento intrapessoal; e a discursiva ou enunciativa, que privilegia a dimensão dialógica e relaciona interação, discurso e conhecimento. 
Essa terceira vertente merece ênfase no presente trabalho, tendo em vista seu caráter promissor, sua congruência com a corrente histórico-cultural e, sobretudo, os avanços que propicia para o estabelecimento de relações do funcionamento de sujeitos com eventos interativos e práticas sociais ou condições macrossociais.

A perspectiva enunciativo-discursiva pode ser identificada pela busca de compor o estudo da microgênese com um conjunto de contribuições da análise do discurso (por exemplo, Orlandi 1987 e Pêcheux 1988) e/ou da teoria da enunciação (por exemplo, Bakhtin 1986). É o caso dos trabalhos de Smolka (1997) e Rojo (1997). Apesar de nuanças que distinguem suas linhas de investigação, as autoras assumem uma perspectiva enunciativodiscursiva que se entrelaça com a análise de minúcias e indícios dos acontecimentos intersubjetivos. De acordo com esses referenciais, os processos são examinados do ponto de vista do fluxo das enunciações, numa ampliação da noção de diálogo para além dos contatos face a face, e são destacadas as práticas sociais, na consideração de condições, tais como a posição de poder dos sujeitos, a imagem dos interlocutores, as formações discursivas, os gêneros discursivos etc. Vários estudos dessa natureza têm focalizado processos de formação de sujeitos nas relações sociais, muitas vezes com a atenção dirigida à construção de conhecimentos, em espaços educativos na escola comum, creches ou ambientes de educação especial (entre outros, cabe citar Carvalho 1997, Cruz 1997, Rocha 1997, Mortimer e Machado 1997, Góes e Souza 1998, De Carlo 1999). A ênfase na dimensão semiótica e intersubjetiva dos acontecimentos (atenção ao diálogo, à mediação semiótica) e o caráter mais compreensivo-interpretativo das discussões são duas das marcas dessas pesquisas.

O estudo de Smolka, Góes e Pino (1995) pode ser lembrado como característico dessa vertente. Trata-se de uma discussão conceitual-metodológica sobre a possibilidade de estudo da constituição do sujeito, que aponta para caminhos de compreensão principalmente por meio da concepção semiótica de Vygotsky e da visão dialógica de Bakhtin. Reconhecendo a necessidade de outras contribuições teóricas (como as de Wallon e Politzer), tal estudo ilustra os pontos de discussão pela análise microgenética de um segmento interativo de crianças durante a atividade de brincar.

Outro exemplo, nesse caso abrangendo um estudo de campo na sala de aula, pode ser encontrado no trabalho de Fontana (1996). A autora focaliza os modos de elaboração conceitual apresentados por crianças em atividades da área de Estudos Sociais, examinando detalhadamente o fluxo das enunciações nos diálogos entre professora - alunos e alunos - alunos. 
Mostra as minúcias do jogo intersubjetivo, no qual os significados se transformam num movimento heterogêneo de conceitualizacão dos participantes. O exame da apropriação de vozes de interlocutores presentes e da impregnação do processo por discursos outros permite identificar diversas condições sociais imediatas e contextuais das elaborações e reelaborações dos interlocutores, que vão se constituindo como sujeitos cognoscentes.

Cabe registrar, ainda, que os autores, além de admitirem a centralidade dos processos dialógicos, buscam salientar, de forma mais geral, o significado da concepção semiótica vygotskyana, como faz Pino (1995). Na direção de dar destaque à questão semiótica, há pesquisas que, mantendo o interesse central nos processos dialógicos, têm também recorrido a formulações do paradigma indiciário formulado por C. Ginzburg. Por se tratar de uma perspectiva de articulação apenas esboçada e que merece ser mais afirmada, vou reportar-me àquele paradigma, para, posteriormente, retomar as visões enunciativo-discursiva e semiótico-indiciária, numa tentativa de configurá-las como um conjunto de versões produtivas da análise microgenética, no âmbito das produções brasileiras inscritas na matriz histórico-cultural.

Passo, então, a uma breve consideração sobre o paradigma indiciário, abordando o texto de Ginzburg (1989) "Sinais. Raízes de um paradigma indiciário".

\section{0 paradigma indiciário}

Ginzburg (1989) discute um paradigma de natureza indiciária, fundamentado na semiótica, o qual "emergiu silenciosamente no âmbito das ciências humanas" (p. 143), configurou-se no final do século XIX, porém já era operante em esferas da atividade humana desde tempos remotos.

Uma retomada histórica que passa pelas semiologia médica, arte divinatória e atividade da caça em períodos longínquos permite ao autor destacar as raízes antigas de um saber que se constrói sobre indícios. Em certo sentido, ele toma o antigo caçador como o precursor dessa forma de saber, dizendo que "por trás desse paradigma indiciário ou divinatório, entrevê-se o gesto mais antigo da história intelectual do gênero humano: o do caçador agachado na lama, que escruta as pistas da presa" (Ginzburg 1989, p. 154).

A elaboração sobre o paradigma indiciário ou semiótico desdobrase por meio de argumentos que apontam a importância dos pormenores considerados negligenciáveis no estudo dos fenômenos. Esses argumentos são apoiados nas formas de conhecimento do perito de arte, do deteti- 
ve e do psicanalista, em referência respectivamente a Giovanni Morelli, Conan Doyle/Sherlock Holmes e Sigmund Freud. Nos três tipos de conhecimento há posturas equivalentes de análise, orientadas para signos (na arte), indícios (na investigação do detetive) e sintomas (na psicanálise).

Em relação ao modelo da ciência moderna, Ginzburg critica o desprezo pelo individual, já que esse modelo toma a investigação de eventos singulares como empecilho para um conhecimento científico rigoroso. A crítica estende-se também a outros pressupostos dessa forma de racionalidade, na busca de leis universais: a crença na transparência da realidade; a separação entre sujeito e objeto; o modo exclusivo de conhecimento sistemático e com regras formais, orientado apenas para as regularidades da natureza. Ginzburg contrapõe a essas visões a riqueza da conjeturalidade do conhecimento humano e a valorização do singular.

Permanecendo por longo tempo marginal ou implícito na esfera científica, o saber conjetural pode ser reconhecido nas mais diversas esferas de atividade da vida cotidiana: dos oleiros, carpinteiros, marinheiros, pescadores etc. Vincula-se a uma intuição que vem dos sentidos e supera o sensorial. Esse saber, quando incorporado ao âmbito da ciência, pode atender a demandas de rigor, mas um rigor que é necessariamente "flexível".

A valorização do singular, já referida, é outro aspecto central do paradigma, tendo em vista que as formas de saber assumidas implicam uma atitude orientada para casos individuais, que devem ser reconstruídos, compreendidos por meio de sinais, signos, pistas, indícios ou sintomas. Mas decifrar e ler pistas é estabelecer elos coerentes entre eventos e, por isso, o componente narrativo faz parte das interpretações indiciárias. Apesar de privilegiar o singular, não se abandona a idéia de totalidade, pois esse modelo epistemológico busca a interconexão de fenômenos, e não o indício no seu significado como conhecimento isolado. A realidade é complexa e opaca, mas "existem zonas privilegiadas - sinais, indícios - que permitem decifrála" (Ginzburg 1989, p. 177), que permitem buscar interconexões e efetuar tentativas de compreensão da totalidade.

As perspectivas enunciativo-discursiva

e semiótico-indiciária da microgênese

Considerando as proposições de Ginzburg, nota-se que algumas delas encontram ilustração justamente na análise microgenética - a atenção a minúcias indiciais, a valorização do estudo de situações singulares 
e a busca de inter-relação da interpretação indiciária com condições macrossociais. Já outras características da microgênese, por não estarem enfatizadas na própria definição, ainda que sejam às vezes referidas, podem ter nesse aporte indiciário argumentos que as configurem melhor - refiro-me à importância do saber conjetural, à função de "decifração" do pesquisador, ao componente narrativo da interpretação. Acrescenta-se, ainda, o destaque conferido ao negligenciável da observação, de modo que a consideração de minúcias (que já está implicada na análise microgenética) passa a requerer uma postura de observação maleável para abranger o que é residual, insignificante à primeira vista.

Nos estudos que buscam estabelecer uma certa vinculação entre as visões enunciativo-discursiva e indiciária, o paradigma delineado por Ginzburg é mencionado para corroborar a importância do olhar para as minúcias (Gentil 1997), da postura investigativa indiciária (Padilha 1997) ou do valor atribuído ao singular (Lacerda 1995). Werner (1997), numa investigação no campo da psiquiatria infantil, destaca esses vários aspectos promissores e atribui um valor mais amplo ao paradigma, sugerindo que ele permite ajudar a superar as limitações do modelo de racionalidade moderna, predominante na medicina. Sua pesquisa emprega a análise microgenética, numa versão semiótica-indicial, para apontar equívocos conceituais e metodológicos nas avaliações diagnósticas de crianças, que, pela classificação oficial, são vistas como portadoras de distúrbios hipercinéticos.

Portanto, quanto à perspectiva indiciária, parece haver uma variação entre pesquisadores, que se reportam a ela apenas para justificar a atenção à própria microgênese, para marcar algum aspecto da linha de análise e interpretação, para fundamentar a construção e a análise de dados etc. Conferem-Ihe, pois, desde um simples papel complementar até um estatuto de referência metodológica fundamental. Apesar dessas diferenças, creio que as tentativas de composição já anunciam a tendência a uma incorporação mais consistente do paradigma indiciário, do ponto de vista conceitual, metodológico e epistemológico.

Tendo em vista que tentei problematizar a definição de análise microgenética apresentada por Wertsch (1985), é importante esclarecer que minha intenção não foi sugerir outra definição de caráter preciso, até porque não é o caso de se "fechar" uma formulação uniforme. Ao contrário, procurei discutir alguns critérios definidores, para, na verdade, expandir a caracterização dessa vertente metodológica e, ao longo da argumentação, sugerir sua distintividade em contraste com outras formas de análise microgenética, de base teórica diversa, ou com outras microanálises em uso. 
Ao abordar as perspectivas que privilegiam os aspectos semióticos ou os discursivos, não estou sugerindo que se trata simplesmente de somá-las, mesmo porque elas apresentam suas especificidades; embora as categorias de signo e discurso se inter-relacionem, não se equivalem. Conforme foi apontado, existem trabalhos que assumem uma orientação enunciativo-discursiva ao olhar a microgênese e outras que fazem, adicionalmente, aproximações com a visão indiciária. É provável que a ampliação de estudos nessas direções propicie mais argumentos para debater e problematizar a pertinência, a congruência e as possíveis lacunas das articulações feitas. Mas meu intuito, neste momento, é reconhecer esse conjunto de "versões" da análise microgenética como um veio teórico-conceitual produtivo, como uma busca de avanços na investigação históricocultural e, em especial, como uma configuração metodológica empregada de maneira mais rica do que se pode inferir das "definições" tipicamente apresentadas. São contribuições de grande valor heurístico, nas quais a visão ampla de dialogia, a preocupação com o funcionamento discursivo e o exame de aspectos indiciais permitem adensar o exame do processo intersubjetivo e expandir as possibilidades de relacionar microeventos e o contexto cultural, com base numa compreensão genético-histórica.

\section{Comentários finais}

Com base nas ponderações feitas, é possível sugerir que a caracterização mais interessante da análise microgenética está numa forma de conhecer que é orientada para minúcias, detalhes e ocorrências residuais, como indícios, pistas, signos de aspectos relevantes de um processo em curso; que elege episódios típicos ou atípicos (não apenas situações prototípicas) que permitem interpretar o fenômeno de interesse; que é centrada na intersubjetividade e no funcionamento enunciativo-discursivo dos sujeitos; e que se guia por uma visão indicial e interpretativo-conjetural. Não se trata de afirmar que essa é uma versão unitária, pois há variações entre pesquisadores. Entretanto, julgo que há uma convergência quanto à composição de delineamentos com ênfase indiciária e dialógica, composição que é profícua como ponto de vista epistemológico e, mais especificamente, como perspectiva de investigação da constituição de sujeitos, concebida no âmbito dos processos intersubjetivos e das práticas sociais.

Finalmente, é importante recordar que boa parte dos argumentos apresentados aqui sobre a análise microgenética, com a contribuição de diferentes autores, não estava nas considerações de Vygotsky ao realizar o estudo de minúcias no plano da microgênese. Mas é preciso reconhecer 
que é de sua obra que se desdobram essas novas possibilidades e que nela pode-se ler o propósito talvez mais característico dessa análise: construir uma micro-história de processos, interpretável somente numa perspectiva semiótica e numa remissão a condições mais amplas da cultura e da história. $E$, quanto às formas de saber requeridas pelo privilegiamento da dimensão semiótica, é curioso notar momentos de semelhança entre certas formulações desse teórico e as idéias indiciárias de Ginzburg, no que concerne ao valor da elaboração conjetural. Ao argumentar que muitas ciências não podem depender da observação direta, Vygotsky (1996) compara a psicologia a campos de conhecimento que dependem de pistas e documentos para estudar fatos; nesse sentido, ele diz: "O psicólogo encontra-se com freqüência na mesma situação do historiador e do arqueólogo e atua como o detetive que investiga um crime que não presenciou" (p. 31, grifo meu).

Uma caracterização de metodologia como a aqui discutida talvez corresponda à condição de "transgressão metodológica" ou "postura imetódica", que, segundo Santos (1997), é uma das marcas do paradigma que está emergindo em oposição ao modelo da racionalidade moderna e do positivismo. Entretanto, em vez da referência ao imetódico, penso que seria mais apropriado falar-se em novas construções sobre modos de conhecer e investigar, as quais, como diz Ginzburg (1989), implicam um rigor e uma cientificidade por definir.

\section{Notas}

1. Não serão tematizadas as tentativas de composição entre as abordagens microetnográfica e microgenética, pois a presente discussão não tem o intuito de cobrir as variadas articulações propostas por pesquisadores; ademais, a preocupação está em marcar especificidades do estudo microgenético na perspectiva histórico-cultural.

2. As publicações de Vygotsky serão referidas com a data da edição traduzida utilizada. Entretanto, nas referências bibliográficas, são feitas indicações da data da publicação original. A exceção estará na referência ao livro $A$ formação social da mente (1984), por se tratar de um conjunto de textos extraídos de diferentes obras, editados e selecionados por uma equipe organizadora (M. Cole e outros), sem especificação das datas originais. A indicação de publicação original também será feita para outros autores, cujos textos são das décadas iniciais do século $X X$.

3. Esse é um dos dois "formatos" dessa metodologia que Wertsch (1985) identifica nos trabalhos de Vygotsky. O segundo formato estaria no exame de processos que duram segundos ou milissegundos (como na consideração do trânsito entre pensamento e linguagem). Essa análise microgenética de curtíssima duração é pouco clara e, a meu ver, está mais ligada a interpretações de Vygotsky sobre as complexas relações entre funções psicológicas, no plano intra-subjetivo. Ademais, não é o formato que tem inspirado os pesquisadores. Por essas razões, não pretendo focalizá-lo aqui. 
The microgenetic analysis in the historic-cultural approach: A perspective for the study of the constitution of subjetivity

\begin{abstract}
This paper focuses on microgenetic analysis as a methodological approach that is inscribed in a historico-cultural and semiotic interpretation of human processes, and is distinct from forms of micro-event analysis connected to other theoretical frameworks. The purpose is to characterize, within the historico-cultural perspective, the trends which articulate the microgenetic level of social interactions to the exam of dialogical-discursive functioning and with propositions of the semiotic-indiciary paradigm. Such trends are very seen as very promising for the investigation of the constitution of the subject, since they enrich the study of intersubjective processes and expand the possibilities of relating details and indicial aspects of specific episodes to macro-social conditions concerning social practices.
\end{abstract}

Bibliografia

ANDRÉ, M.E.D.A. "Tendências atuais da pesquisa na escola". Cadernos Cedes 43, 1997.

BAKHTIN, M. (Volochinov). Marxismo e filosofia da linguagem. São Paulo: Hucitec, 1986 (texto de 1929).

CARVALHO, M.F. "Aspectos da dinâmica interativa no contexto da educação de crianças e jovens com Síndrome de Down". In: GÓES, M.C.R. e SMOLKA, A.L.B. (orgs.). A significação nos espaços educacionais: Interação social e subjetivação. Campinas: Papirus, 1997, cap. 7.

CASTORINA, J.A.; LENZI, A. e FERNÁNDEZ, S. "Alcance do método de exploração crítica em psicologia genética". In: CASTORINA, J.A. e colabs. Psicologia genética: Aspectos metodológicos e implicações pedagógicas. Porto Alegre: Artes Médicas, 1988, cap. 4.

CRUZ, M.N. "Multiplicidade e estabilização dos sentidos na dinâmica interativa: A convencionalização das primeiras palavras da criança". In: GÓES, M.C.R. e SMOLKA, A.L.B. (orgs.). A significação nos espaços educacionais: Interação social e subjetivação. Campinas: Papirus, 1997, cap. 3.

DE CARLO, M.M.R.P. Se essa casa fosse nossa...Instituições e processos de imaginação na educação especial. São Paulo: Plexus, 1999.

FONTANA, R.C. A mediação pedagógica na sala de aula. Campinas: Autores Associados, 1996. 
GENTIL, M. "Em cima da hora? O que é isso? Palavras em uso e a elaboração conceitual em um contexto pré-escolar". Dissertação de mestrado. Campinas: Faculdade de Educação, Unicamp, 1997.

GINZBURG, C. Mitos, emblemas, sinais: Morfologia e história. São Paulo: Companhia das Letras, 1989.

GÓES, M.C.R. e SOUZA, R.M. "A linguagem e as 'estratégias comunicativas' na interlocução entre educadores ouvintes e alunos surdos". Distúrbios da Comunicação, 10(1), 1998, pp. 59-76.

LACERDA, C.B.F. Inter-relação entre oralidade, desenho e escrita. São Paulo: Cabral, 1995.

LURIA, A.R. "Vigotskii". In: VYGOTSKY, L.S.; LURIA, A.R. e LEONTIEV, A.N. Linguagem, desenvolvimento e aprendizagem. São Paulo: Ícone/Edusp, 1988a, cap. 2.

LURIA, A.R. "Diferenças culturais de pensamento". In: VYGOTSKY, L.S.; LURIA, A.R., e LEONTIEV, A.N. Linguagem, desenvolvimento e aprendizagem. São Paulo: Ícone/Edusp, 1988b, cap. 3.

MEIRA, L. "Análise microgenética e videografia: Ferramentas de pesquisa em psicologia cognitiva". Temas em Psicologia 3, 1997, pp. 59-71.

MORTIMER, E.F. e MACHADO, A.H. "Múltiplos olhares sobre um episódio de ensino: Por que o gelo flutua na água?". Anais do Encontro sobre Teoria e Pesquisa em Ensino de Ciências - Linguagem, Cultura e Cognição. UFMG, 1997, pp. 139-162.

ORLANDI, E.P. A linguagem e seu funcionamento. Campinas: Pontes, 1987.

PADILHA, A.L. Possibilidades de histórias ao contrário - ou como desencaminhar o aluno da classe especial. São Paulo: Plexus, 1997.

PÊCHEUX, M. Semântica e discurso: Uma crítica à afirmação do óbvio. Campinas: Ed. da Unicamp, 1988.

PIAGET, J. A representação do mundo pela criança. Rio de Janeiro: Record, 1978 (texto de 1926).

PINO, A. "Semiótica e cognição na perspectiva histórico-cultural". Temas em Psicologia 2, 1995, pp. 31-40.

ROCHA, M.S.L. "O real e o imaginário no faz-de-conta: Questões sobre o brincar no contexto da pré-escola". In: GÓES, M.C.R. e SMOLKA, A.L.B. (orgs.). A significação nos espaços educacionais: Interação social e subjetivação. Campinas: Papirus, 1997, cap. 4.

ROJO, R.H.R. "Enunciação e interação na ZPD: Do non sense à construção dos gêneros de discurso". Anais do Encontro sobre Teoria e Pesquisa 
em Ensino de Ciências - Linguagem, Cultura e Cognição. UFMG, 1997, pp. 95-109.

SANTOS, B.S. Um discurso sobre as ciências. Porto: Afrontamento, 1997.

SMOLKA, A.L.B. "Esboço de uma perspectiva teórico-metodológica no estudo de processos de construção de conhecimento". In: GÓES, M.C.R. e SMOLKA, A.L.B. (orgs.). A significação nos espaços educacionais: Interação social e subjetivação. Campinas: Papirus, 1997, cap. 2.

SMOLKA, A.L.B.; GÓES, M.C.R., e PINO, A. "The constitution of the subject: A persistent question”. In: WERTSCH, J.V.; DEL RÍO, P., e ALVAREZ, A. (orgs.). Sociocultural studies of mind. Cambridge, Mass.: Cambridge University Press, 1995, cap. 7.

STREECK, J. Social order in child communication. A study in microethnography. Amsterdã/Filadélfia: John Benjamin's Publishing Co., 1983.

VYGOTSKY, L.S. Formação social da mente. São Paulo: Martins Fontes, 1984.

VYGOTSKY, L.S. The Genesis of the higher mental functions. In: WERTSCH, J. V. (org.) The problem of activity in Soviet Psychology. [s.r]

VYGOTSKY, L.S. "Les bases epistemologiques de la psychologie". In: BRONCKART, J.P. et al. Vygotsky aujourd'hui. Neuchâtel: Delachaux \& Niestlé, 1985, cap. 1 (texto de 1931).

VYGOTSKY, L.S. Imaginación y el arte en la infancia. Cidade do México: Hispánicas, 1987a (texto de 1930).

VYGOTSKY, L.S. Problems of general psychology. The collected works of L.S. Vygotsky, vol. 1. Nova York: Plenum, 1987b (texto de 1934).

VYGOTSKY, L.S. Teoria e método em psicologia. São Paulo: Martins Fontes, 1996, cap. 1 (texto de 1926).

VYGOTSKY, L.S. e LURIA, A.R. Estudos sobre a história do comportamento: O macaco, o primitivo e a criança. Porto Alegre: Artes Médicas, 1996 (texto de 1930).

WERNER, J. "Transtornos hipercinéticos: Contribuições do trabalho de Vygotsky para reavaliar o significado do diagnóstico". Tese de doutorado. Campinas: FCM/Unicamp, 1997.

WERTSCH, J.V. Vygotsky and the social formation of mind. Cambridge, Mass.: Harvard University Press, 1985.

WERTSCH, J.V. Voices of the mind. A sociocultural approach to mediated action. Cambridge, Mass.: Harvard University Press, 1991.

WERTSCH, J.V. e HICKMANN, M. "Problem solving in social interaction: A microgenetic analysis". In: HICKMANN, M. (org.). Social and functional approaches to language and thought. Nova York: Academic Press, 1987. 